\title{
¿CUERPO A CUERPO? MODOS DE TRANSMISIÓN EN LA FORMACIÓN DE BAILARINES DE DANZA CONTEMPORÁNEA Y ACRÓBATAS EN LA CIUDAD DE LA PLATA (BUENOS AIRES, ARGENTINA)
}

\author{
BODY TO BODY? TRANSMISSION MODES IN CONTEMPORARY DANCERS AND \\ ACROBATS' TRAINING IN THE CITY OF LA PLATA (BUENOS AIRES, ARGENTINA)
}

\author{
¿CORPO A CORPO? MODOS DE TRANSMISSÃO NA FORMAÇÃO DE \\ BAILARINOS/AS DE DANÇA CONTEMPORÂNEA E ACROBATAS \\ NA CIDADE LA PLATA (BUENOS AIRES, ARGENTINA)
}

Mariana Lucía Sáez ${ }^{1}$

Resumen

Entre 2012 y 2016, realicé un trabajo etnográfico comparativo con enfoque en el cuerpo, en los circuitos de la danza contemporánea y las artes circenses en la ciudad de La Plata (Buenos Aires, Argentina). Este dio lugar a mi tesis doctoral, en la que analicé los procesos de formación de bailarines y acróbatas circenses, atendiendo las relaciones entre los modos de hacer-cuerpo de las clases y las experiencias corporales específicas que se habilitan en cada uno de estos contextos. Retomando ese trabajo de campo, basado en la observación, participación, descripción y análisis de clases de danza contemporánea y de acrobacia (aérea y de piso), en este artículo comparto algunos de los resultados de mi investigación doctoral, enfocándome específicamente en los modos de transmisión que se ponen en juego en los procesos de formación de los artistas, caracterizando las distintas estrategias pedagógicas utilizadas y los modos en que allí se movilizan diversos recursos corporales y lingüísticos diferencialmente articulados.

Palabras clave: antropología de la danza; formación; cuerpo; lenguaje; movimiento

Between 2012 and 2016, I made a comparative ethnographic work focused on the body, in contemporary dance and circus arts circuits in the city of La Plata (Buenos Aires, Argentina). This work resulted in my doctoral thesis, in which I analyzed the training processes of contemporary dancers and circus acrobats, attending to the relationships between the modes of body-making in class and the specific corporal experiences that are enabled in each one of these contexts. Returning to this field work, in this article I share some of the results of my doctoral research, focusing on the modes of transmission in the training processes, characterizing the pedagogical strategies used and the ways in which different body and linguistic resources are used and articulated.

Keywords: anthropology of dance; training; body; language; movement

1 Licenciada en Antropología por la Universidad Nacional de La Plata. Doctora de la Universidad de Buenos Aires (Facultad de Filosofía y Letras, con orientación en Antropología). Centro Interdisciplinario Cuerpo, Educación y Sociedad, Instituto de Investigaciones en Humanidades y Ciencias Sociales, Universidad Nacional de La Plata, Argentina, Consejo Nacional de Investigaciones Científicas y Técnicas. Correspondencia: marianasaezsaez@gmail.com 
Entre 2012 e 2016, realizei um trabalho etnográfico comparativo focado no corpo, nos circuitos de dança contemporânea e as artes circenses na cidade de La Plata (Buenos Aires, Argentina). Este trabalho deu passo à minha tese de doutorado, na qual analisou os processos de formação de dançarinos e acrobatas de circo, abordando as relações entre as formas de fazer-corpo nas aulas e as experiências corporais específicas que são habilitadas em cada um desses contextos. Retomando aquele trabalho de campo, baseado na observação, participação, descrição e análise das aulas de dança contemporânea e de acrobacia (aérea e terrestre), neste artigo compartilho alguns dos resultados da minha pesquisa de doutorado, concentrando especificamente nas formas de transmissão que se põem em jogo nos processos de formação dos e das artistas, caracterizando as diferentes estratégias pedagógicas utilizadas e as maneiras em que ali se movimentam diversos recursos corporais e linguísticos diferencialmente articulados.

Palavras-chave: antropologia de a dança; formação; corpo; linguagem; movimento

Fecha de recepción: 15 de febrero de 2019

Fecha de evaluación: 08 de marzo de 2019

Para citar este artículo:

Sáez, M. L. (2019). ¿Cuerpo a cuerpo? Modos de transmisión en la formación de bailarines de danza contemporánea y acróbatas en la ciudad de La Plata (Buenos Aires, Argentina). Lúdica Pedagógica, 29, 23-34. https://doi.org/10.17227/ludica.num29-11082 


\section{INTRODUCCIÓN}

Entre 2012 y 2016, realicé un trabajo etnográfico comparativo con enfoque en el cuerpo, en los circuitos de la danza contemporánea y las artes circenses en la ciudad de La Plata (Buenos Aires, Argentina). Este dio lugar a mi tesis doctoral (Sáez, 2017), en la que analicé los procesos de formación de bailarines y acróbatas circenses, atendiendo las relaciones entre los modos de hacer-cuerpo de las clases y las experiencias corporales específicas que se habilitan en cada uno de estos contextos, reiterándose e intensificándose con el transcurso del tiempo y de la continuidad de la práctica. De este modo, caractericé corporalidades y subjetividades propias de cada práctica analizada, a las que identifiqué como "el cuerpo disponible del bailarín" y "el cuerpo entrenado del acróbata".

Retomando ese trabajo de campo, basado en la observación, participación, descripción y análisis de clases de danza contemporánea y de acrobacia (aérea y de piso), en este artículo me propongo compartir algunos de los resultados de mi investigación doctoral, enfocándome específicamente en los modos de transmisión que se ponen en juego en los procesos de formación de los artistas, caracterizando las distintas estrategias pedagógicas utilizadas y los modos en que se movilizan diversos recursos corporales y lingüísticos diferencialmente articulados.

Sistematizaré, entonces, los modos de transmisión: "cuerpo a cuerpo" (que incluye el aprendizaje típicamente mimético, a través de la observación y copia del movimiento, y el aprendizaje a través del contacto o la manipulación del cuerpo), "cuerpo-palabra-cuerpo" (Mora, 2011) (que implica la mediación de la palabra, incluyendo aquí el uso metafórico del lenguaje, de particular importancia en el caso de la danza contemporánea) y "cuerpo-voz-cuerpo" (que se vincula al uso de sonidos, onomatopeyas y cantos, en los cuales la voz tiene un lugar en la transmisión de información respecto del movimiento por realizar, pero que no está asociada directamente a un significado verbal).

A partir del análisis de estos modos de transmisión, destaco la coexistencia de palabras y movimientos en el aprendizaje de estas prácticas corporales artísticas y discuto algunas afirmaciones (que circulan, tanto en el propio campo de la danza, como en algu- nas de las investigaciones que la abordan) que postulan que la palabra ocupa un lugar secundario en la danza, y que el movimiento puede estudiarse independientemente de los discursos (Bourdieu, 1996; Fiske, 1997), afirmaciones que podrían hacerse extensivas a las prácticas circenses y, en particular, a las acrobacias.

\section{DANZA CONTEMPORÁNEA. MUCHAS MANERAS DE LLEGAR}

El trabajo con series o secuencias de movimientos que se repiten a lo largo de varios encuentros es una característica distintiva de las clases de técnica de danza contemporánea:

Las clases son principalmente de técnica de la danza contemporánea, sin por ello dejar de lado recursos provenientes de la improvisación que, creo, alimentan la técnica. [...] Uno se acerca a la técnica mediante la repetición y la secuenciación de movimientos, gestos, esquemas. Es en la repetición en donde se genera la dialéctica de la técnica: cada repetición abre preguntas que la siguiente ejecución podrá o no respondernos, para que así surjan nuevas preguntas que en el infinito del movimiento podremos ir contestando, preguntando y repreguntando (Julia Aprea, comunicación personal, 9 de noviembre de 2015).

Esta infinita serie de preguntas y respuestas sobre la repetición de un (¿mismo?) movimiento sitúa la atención, el registro y la conexión con el propio cuerpo como elementos característicos de la concepción de la danza contemporánea y su modo de comprender el cuerpo.

A partir de la repetición de un mismo movimiento, o de una secuencia de movimientos, se van produciendo cambios en el cuerpo: cambios en la temperatura corporal general o de ciertas partes; cambios en la respiración, ya sea en los usos de aquella durante la realización de los ejercicios o en el ritmo respiratorio; cambios en la frecuencia cardiaca; sensaciones de pesadez, liviandad, hormigueo o cansancio (general o en alguna parte del cuerpo en particular). El registro de esos cambios se convierte en insumo para que la repetición no sea "siempre igual".

Por otra parte, a la par de las "nuevas sensaciones", estos movimientos que se registran y se repiten una 
y otra vez van generando habitualidades en el cuerpo. Sin embargo, y más allá de que se produzcan patrones de movimiento claramente identificables para quien observa las clases (y también para quienes las realizan), en los modos de valorar estas repeticiones el foco no está puesto en la habitualidad o en lo que se mantiene igual en la repetición, sino en la diferencia, en lo particular, en las "nuevas preguntas" y en la posibilidad de que cada alumno se "apropie" del movimiento.

Al recurrir a fragmentos de notas de campo provenientes del contexto de la clase, observamos que se cuelan en la descripción técnica elementos vinculados a sus modos de transmisión. Nos centraremos ahora específicamente en ellos.

En general, el funcionamiento de la clase es el siguiente: Iván muestra la secuencia, la marcamos todos juntos y nos ponemos de a dos para "estudiarla" (y ahí cada dúo puede ver cómo se maneja. En mis experiencias de dúo, lo que hicimos fue o bien hacerlas juntas e irnos copiando y comentando recíprocamente, o bien una mira a la otra y le comenta o corrige para luego cambiar de roles). En general la hacemos un par de veces, aumentando la velocidad cada vez. Para las diferentes secuencias, formamos diferentes parejas de estudio.

Cuando alguien tiene una duda, y pregunta, Iván la hace mostrar, para que "muestre la pregunta". Y hace comentarios y correcciones. En general, Iván, al responder a las dudas, muestra, a veces una manera correcta, a veces una incorrecta, exagerando algunas situaciones o errores. También cada tanto, medio al azar, hace mostrar a alguien algo, para "estudiar" mirándolo (Nota de campo del 25 de febrero de 2013).

Luego empezamos a trabajar, a partir de ese movimiento sencillo, una rolada hacia atrás. Es una vuelta por un hombro, pasando por la posición de vela y bajando arqueando la columna (se apoya primero el pecho, luego la panza, la cadera y, en últimas, las piernas). Trabajábamos de a dos: uno lo hacía y el otro acompañaba con las manos y sostenía las piernas en la vela, para ayudar a la vuelta sobre los hombros y sostener la caída. Yo trabajé con Eliana. Ella ya lo había hecho, sola, así que le salía muy bien y muy fácil. Yo no lo había hecho nunca, ni sola ni con ayuda. Pero, más o menos, fue saliendo, por lo menos sin golpes. Cada pareja, por su cuenta, lo probó y, después, lo mostró, cambiando de roles. Volvió a mostrar Iván con Mariana, para despejar algunas dudas, y ahí vi que solo le agarraba una pierna, no las dos, como estábamos haciendo (o intentando hacer) con Eliana. Se lo dije a ella, y empezamos a probar, agarrándonos una pierna sola, y resultó más fácil entender el movimiento, así, con un poco menos de ayuda. Yo sentí la diferencia en la bajada: si bajaba con las dos piernas sujetadas por mi compañera, era ella la que me bajaba o me sostenía la bajada; en cambio, con una pierna sola, podía sentir yo cómo iba bajando y percibir mejor el arco necesario de la espalda y el tipo de "esfuerzo" necesario (Nota de campo del 26 de febrero de 2014).

Pienso que es importante conocer sobre anatomía. Algunas docentes de danza me decían "Hombros hacia atrás y hacia abajo", me era inevitable sacar el pecho hacia afuera. Hasta que leí sobre cómo [se] puede rotar hombro hacia delante y hacia atrás, acompañada de un dibujo en un libro de anatomía, y ahí entendí todo (Cirila Ferron, comunicación personal, 29 de mayo de 2014).

Bel: El resto de las chicas, más o menos, lo llevan, pero ella tiene algunos problemas que me preocupan.

Yo: Sí, yo también lo noté y no me animé a hacer mucho. Me parece que la forma es tocando.

Bel: Sí, puede ser. Pero son muchas cosas...

Rena: Sí, falta de articulación en la parte baja de la columna...

Bel: Sí, como rectificada...

Yo: $\mathrm{Y}$ las rodillas que se le van para adentro...

Bel: Y algo en los hombros también...

Rena: Sí, hablando, me parece que por ahora no hizo efecto... como que no registraba...

Yo: Para mí hay que tocar, pero no me animé a hacerlo. Es raro en la primera clase, bombardearla con tanta cosa...

Bel: Sí, es mucha información toda junta... Renata estuvo tocando a algunas, y ayudó... No sé qué podemos hacer para trabajar eso... 
Rena: Para lo de la columna, se me ocurre que podemos hacer de a dos, bajar y subir vértebra por vértebra, guiadas por los deditos del compañero por la columna...

Bel: Sí, eso puede servir...

Yo: Y bueno, iremos viendo en las clases cómo corregir...

(Nota de campo del 8 de abril de 2014).

Como se observa en esta selección de fragmentos de materiales de campo, los modos y las estrategias para la transmisión de aspectos técnicos de la danza contemporánea son variados.

En primer lugar, nos encontramos con la copia mimética, en la que el docente muestra una forma o secuencia de movimientos que los alumnos reproducen. Esta modalidad también puede darse entre alumnos que se muestran y se "pasan" las secuencias o partes de ellas. La copia puede ser simultánea, es decir, que docente y alumnos (o entre alumnos) realicen la secuencia al mismo tiempo, copiándose durante el hacer; o diferida, en la que el docente (o el alumno) muestra la secuencia, y los alumnos la realizan después. Por otra parte, mostrar una forma o una secuencia puede usarse como un modo de mostrar o preguntar al docente para recibir comentarios o correcciones (que pueden, a su vez, ser verbales o corporales).

Este modo de transmisión parecería ir en contra de los principios de búsqueda de movimiento propio o apropiación del movimiento. Sin embargo, muchas veces va acompañado de expresiones vinculadas a que cada uno "busque" la manera más "cómoda" para su cuerpo, o encuentre el modo en que le resulta más sencillo y menos esforzado de realizar. Así, aunque el objetivo pueda ser llegar a una forma más o menos determinada, se considera que el camino para alcanzarla y comprender el movimiento no es uno solo y debe ser experimentado personalmente.

Por otra parte, la mayoría de las veces el "marcado" de movimientos va acompañado de expresiones verbales de distinto tipo que contribuyen tanto a esta búsqueda personal ya mencionada, como a la comprensión del movimiento por otros canales y a su valoración en términos de corrección técnica y estética. En este sentido, encontramos expresiones analí- ticas que describen el movimiento y sus mecanismos ("Empujo con los pies y levanto la cadera hacia el techo, paso la mano y el brazo por debajo, por ese espacio que se generó, y roto el hombro"), referencias a cuestiones anatómicas o biomecánicas ("Busquen abrir la articulación, para que el fémur pueda rotar desde su cabeza"), uso de metáforas, imágenes y sensaciones ("Los pies espían y se van abriendo camino entre obstáculos", "Los dedos como gotas de lluvia", "Como si me soplara un viento") que indican lo qué es correcto e incorrecto ("Que no pase eso, los brazos se mantienen dentro del campo visual, no se van más atrás"), e incluso lo que es lindo o feo ("Ahí estuvo mejor, se vio más lindo”, “SSí! ¡Qué lindo eso!”). Cabe mencionar aquí otros dos usos recurrentes de la voz en las clases: el uso de sonidos u onomatopeyas (por ejemplo, “¡Tac! ¡Tac!”, para indicar y acompañar el movimiento cortado de flexión de cadera, primero, y de rodilla, a continuación) y el canto o tarareo del movimiento ("Y vooooy y vuelvo y giiiiiiiiiro ysaltoybajojya!", indicando la temporalidad del movimiento).

En su trabajo sobre la formación dancística en el circuito independiente de la ciudad de Buenos Aires (Argentina), Osswald (2011) registra la importancia que adquiere la palabra hablada por la docente - y en menor medida por la intervención de los alumnos - y analiza la performance comunicacional docente y los actos de escucha realizados por los alumnos.

Además de mostrar y hablar, otro recurso que utilizan los docentes es el contacto corporal, tocando o movilizando distintas partes del cuerpo de los alumnos. Esta modalidad es, en general, correctiva, porque indica tensiones que deben aflojarse, recorridos que deben realizarse o posiciones adecuadas para alguna parte del cuerpo. Pero también puede hacerse un uso exploratorio y de registro del contacto corporal. Esta modalidad puede usarla el docente sobre un alumno, tocando algunas partes de su cuerpo mientras realiza un movimiento, para que lleve a ellas su atención conciente. Además, es una modalidad de trabajo frecuente entre parejas de alumnos, en la que, a partir de distintas consignas, uno acompaña a otro en su movimiento, dándole peso en algunas zonas, ofreciendo puntos de apoyo o de contacto con el propio cuerpo, o movilizando el cuerpo del otro por manipulación o aplicación de impulsos. 
Por último, quisiera detenerme un momento en el uso metafórico del lenguaje, que tiene un lugar especialmente relevante. Como hemos visto, en el circuito de la danza contemporánea, el cuerpo es dinámico y cambiante. En este sentido, es difícilmente descrito por conceptos solidificados. Muchos movimientos que pueden parecer semejantes vistos de afuera no tienen, sin embargo, un nombre, y son más bien descritos a través de palabras que refieren sensaciones, imágenes o metáforas. Estos usos del lenguaje, con su apertura de sentidos y el trabajo de interpretación que implican, se ajustan más a esta concepción del cuerpo. Un cuerpo que tiene sentidos múltiples a ser interpretados, pero que no puede ser completamente descifrado. De este modo, el valor de la propia experiencia del cuerpo, la apropiación del movimiento, la importancia de la improvisación, el uso metafórico del lenguaje y la falta de denominaciones para los movimientos hacen parte de un modo de entender el cuerpo, el movimiento y la danza.

\section{ACROBACIA. ENTRENAR, REPETIR, INSISTIR}

El aprendizaje de la técnica acrobática encuentra en el "entrenamiento" un espacio social y modo de formación corporal característico, que implica la incorporación gradual de los principios técnicos centrales: "alineación", "postura” y "empuje”, logrando así que la práctica se haga cuerpo. En este proceso, se ponen en juego diferentes estrategias y modalidades de enseñanza, transmisión y aprendizaje.

Después, Uki nos dijo que probáramos otra subida. Creo que le llamó cosida, o algo así. La habíamos probado también alguna vez con Estefi, pero no más de dos clases, como mucho. Recuerdo que me había parecido muy difícil y muy cansadora.

Uki le pidió a Vero que la muestre. Vero le dijo que no sabía cuál era.

—La que hacés siempre y te sale re bien -le respondió Uki.

Vero subió a la tela y empezó a subir normal. Uki le mostró en otra tela cuál era, desde abajo nomás, y ahí Vero siguió subiendo con esta subida "cosida".

- Primero no me acordaba ni cómo era ni cómo se llamaba, pero es verdad, es lo que hago siempre para subir.
Traté de hacerla una vez, y no me daba cuenta para qué lado tenía que enroscar la pierna y meter el pie. Le pregunté desde la tela a Vero que estaba cerca.

—A ver... No se cómo explicarte, lo tengo que hacer.

Ahí yo me bajé de la tela y ella empezó a subir.

-Por eso no doy clases yo, porque no sé explicar, tengo que mostrar. Por eso doy solo el entrenamiento (Nota de campo del 25 de febrero de 2015).

Después de eso, Uki nos marcó la llave de cintura. Subió a la tela, se balanceó hacia un lado, al mismo tiempo que elevaba la cadera y separaba las piernas, enlazando la tela en una de ellas, y terminando el movimiento de costado con la tela pasando entre las piernas y cayendo por arriba de su cadera. Nos la mostró una vez normal, y después la hizo otra vez en cámara lenta. Nos dijo que podíamos estar toda la clase para que salga, o incluso varias clases, que tuviéramos paciencia.

Estuve tratando de hacerla, pero no me salía, y si lograba enganchar la tela, me quedaba siempre muy abajo, en las piernas, y no en la cadera. No entendía por dónde tenía que pasar la tela, de qué lado pararme, qué tela por dónde. Le pedí a una de las chicas a las que le salía bien que me explicara por dónde pasaba la tela. Ella me fue mostrando, y yo, parada en el piso, la fui pasando con las manos, para tratar de entender el recorrido. Eso me ayudó a poder entender qué pierna tenía que ir adelante y cuál atrás, por dónde pasar la tela y hacia dónde debía colgar el cuerpo.

Probé arriba una vez más, pero no me salía. Otra de las chicas me dijo que Estefi le había explicado cómo hacerla con un movimiento de rodillas, pero no se acordaba bien como para explicarme.

En eso justo llegó Estefi (venía de Buenos Aires porque los martes a la noche ensaya una obra y se queda a dormir allá). Se acercó a saludarnos a la tela.

—Están probando la llave de cintura, ¡muy bien!

Yo le dije que no tan bien, que no me salía.

— ¿A ver? — Me dijo y me señaló la tela.

Traté de armarla, y no pude. Ahí se puso al lado mío y me dijo: 
-Pensá que es un cambio de rodillas. Sube primero tu rodilla hábil y, después, la otra, enganchando la tela -y me muestra el movimiento, parada al costado mío, pero sin la tela. Lo pruebo, logro enganchar la tela, pero me queda baja en las piernas.

-Bien, ahí va. Ahora, para que la tela baje a la cola, tenés que estirar la pierna para abajo.

Lo intenté, pero no me salió.

—Más estiradas las piernas y más hacia abajo, no en diagonal.

Lo probé una vez más, y fue algo mejor.

(Nota de campo del 25 de marzo de 2015).

-Vamos a hacer verticales a sostener por tiempo. Pónganse de a dos, así están tranquilos que alguien los cuida.

Me junto con Nadia, que habíamos quedado cerca. Yo hago primero. Nadia se pone al costado, y me sostiene de los tobillos cuando subo. Después, se corre detrás de mí y pone su mano entre mis pies. Yo se la aprieto, y eso se sirve como punto de apoyo y sostén. Mientras estamos sosteniendo las verticales, Jose y Mati van pasando por las duplas y van haciendo correcciones.

Jose se acerca a mí y me dice que todavía tengo que empujar más de hombros.

-Acordate del gato enojado. Abrí más las escápulas y cerrá costillas - me dice mientras me pone la mano en la parte alta de la espalda-. Pensá en empujar mi mano.

Trato de hacer eso. Siento que aumenta la tensión en los brazos y en los abdominales.

— ¡Eso! Ahí va, Mari. Pero ojo que te estás carpando. Abrí las ingles.

(Nota de campo del 22 de junio de 2015).

Estamos practicando la sentadita. Flor hace una, pero no le sale: en vez de quedar sentada — de ahí el nombre-, queda colgando. Estefi la ve y se acerca.

—Aflojaste el plegado, Flor. Hacelo de nuevo, dale.
Flor se vuelve a subir a la tela. Invierte, pone corva, hace el pañal, cambia la mano, y pasa la tela a la cadera opuesta.

-Ahora plegate y hacé postura.

Flor se pliega, y lleva el brazo libre paralelo a la oreja.

-Acá no tenés que abrir la pierna, sino llevarla a la cara -le agarra la pierna, y se la acomoda-. Y ahora cuando sueltes la corva, no aflojes la postura, mantenete en ese plegado. Dale, saca corva...

Flor saca la corva, se da vuelta y queda - casisentada - se termina de sentar agarrándose con la mano de la tela-.

(Nota de campo del 8 de octubre de 2015).

Estos cuatro fragmentos de notas de campo dan cuenta de diferentes modalidades de transmisión del saber-hacer de la acrobacia, que conllevan, a su vez, distintas formas de aprehenderlo e incorporarlo.

En el primer caso, hay una transmisión predominantemente mimética, basada en la copia de formas, donde la palabra tiene un lugar secundario y donde no hay contacto corporal. Este tipo de aprendizaje corporal-mimético es el mismo que se pone de manifiesto cuando se "aprende de internet" o "mirando videos". Es frecuente que en los entrenamientos se miren videos subidos a YouTube, Instagram u otras redes sociales, y se copien los movimientos como una forma de "sacar" el truco. También filmarse con los celulares y compartir esos videos en los grupos de Facebook o Whatsapp es una práctica habitual.

En el segundo fragmento, aparece una forma distinta de transmisión, que, mediada por la palabra, analiza el movimiento y lo descompone en unidades más pequeñas. El uso de la palabra posibilita, también, la transmisión de cosas que "uno no puede hacer, pero puede aprender y transmitir":

Y hay cosas que me cuesta mostrarlas. Las cosas de contorsión que mi cuerpo no las puede reproducir. En todo caso, se las paso, se las voy diciendo. Pero mi pie no me llega a mi cabeza; por más fuerza que haga, no llega, y no lo puedo mostrar. [...] De hecho, yo tomé tiempo clases con una contorsionista y aprendí un montón de cosas de contorsión que no las hago pero ni por joda. Pero las puedo 
transmitir con la palabra, y si no es con la palabra, le digo "Mirá, más o menos es así: este pie ponele que está acá, pero tendría que estar como por acá" [...] y más o menos lo voy guiando. Y si no, engancho a alguna que sé que tiene un cuerpo que me pueda seguir con lo que yo le voy diciendo, y así lo mostramos (Estefanía Apas, comunicación personal, 5 de agosto de 2014).

Por su parte, la comprensión en este segundo caso implica el pasaje de una información que es analítica-verbal a una comprensión corporal. Este pasaje implica también un pasaje en la temporalidad: de la sucesión verbal a la ejecución simultánea en el acto. No se puede pensar "en el momento", debe hacerse. Así lo indica Jose, en sus clases, al enseñar acrobacias de pasaje como el rondó: "Ahí es como un reflejo. No lo piensen. Si lo piensan, se les pasó el momento".

En el tercer y cuarto fragmentos presentados al inicio de este apartado, aparece un nuevo elemento: el contacto con el cuerpo del otro, como forma de transmisión que permite la incorporación del movimiento. En el primero de estos, como contacto, y en el segundo, como manipulación del cuerpo del otro. En este caso, la comprensión está dada por la percepción de una serie de modificaciones corporales, hasta llegar a la situación deseada.

Estas distintas estrategias y modalidades de transmisión y de aprendizaje se combinan dinámicamente en los procesos formativos, y tanto docentes como alumnos recurren a ellas de manera alternativa:

Sí, en realidad cada ejercicio tiene su particularidad de cada uno. Sea vos, cómo le decís, esto se arma así; fijate tal y tal cosa, de cómo agarrarte, de cómo sostenerte, desde dónde. Pero después lo que tiene en sí de cómo agarrarte con una mano y otra, cuestiones que en realidad, por condiciones físicas capaz, o por comodidad, depende cómo le quede más cómodo y no hace al ejercicio en sí. Esas cosas sí, se da todo el tiempo de que no es taxativo ningún ejercicio. Esa apertura está todo el tiempo, de buscar, por acá, por acá, por allá... Pero la vuelta se la termina de dar cada uno, y lo más rico del aprendizaje es eso. Yo, de hecho, aprendo un montón dando clase. [...] Entonces, en el dar clases me pasó eso, que todo el tiempo rever, rever lo mismo, y te queda, sí. Y hay gente que lo entiende de una forma y hay gente que no (Lucio Cabadas, comunicación personal, 18 de octubre de 2014).
Otro elemento que aparece nuevamente aquí es la repetición. Seguir probando, seguir intentando, buscando nuevas estrategias de transmisión y de comprensión, pero repitiendo el ejercicio:

Y ese es el trabajo, se experimenta mediante el ensayo y error, con el trabajo... el buscar, el machacar. [...] Tengo que ver los avances, lo que voy progresando, lo que voy haciendo, soy muy terco, ya voy a sacarlo en algún momento, machaco, machaco, machaco y hasta que lo saco de alguna manera, y a veces machaco, voy otro día y me doy cuenta de que pensé que lo había sacado, pero en realidad no lo había sacado, que pensé que lo había sacado, pero lo estaba haciendo mal, y así todo el tiempo, en un montón de cosas me sigue pasando (Matías Yaber, comunicación personal, 7 de enero de 2016).

\section{¿CUERPO A CUERPO?}

En su conferencia de 1983, "Programa para una sociología del deporte”, Pierre Bourdieu (1996) propone, tal como el título lo indica, algunos lineamientos para el desarrollo de una sociología del deporte. Lo que resulta interesante de ese texto, en relación con lo planteado hasta aquí, es que en su argumentación establece un paralelismo del deporte con la danza, a la cual, más allá de su condición como práctica artística, la considera una práctica corporal, es decir, una práctica basada en una comprensión y un aprendizaje que pasa eminentemente por el cuerpo, y propone que su estudio sea encarado con base en esta dimensión. Así, plantea que la danza y el deporte -y nosotros podríamos aquí incluir a las artes circenses - comparten el hecho de ser prácticas que se transmiten buscando que el cuerpo comprenda directamente lo que debe hacer, a través de "una comunicación silenciosa, práctica, de cuerpo a cuerpo" (p. 182). En palabras de Löic Wacquant, quien analizó el proceso de incorporación de la práctica del boxeo:

[...] es el cuerpo el que comprende y aprende, el que clasifica y guarda la información, encuentra la respuesta adecuada en el repertorio de acciones y reacciones posibles y se convierte en última instancia en el verdadero 'sujeto' (si es que hay uno) de la práctica (2006, p. 97).

A partir de las observaciones que he realizado, los espacios formativos de la danza contemporánea y de 
las acrobacias no son justamente "silenciosos", como parece suponer Bourdieu. Podría decir, incluso, que las clases de acrobacia son, en cierta medida, bulliciosas: muchos de los trabajos se realizan en pequeños grupos, y los integrantes de cada uno mantienen conversaciones simultáneas entre sí. Las clases de danza contemporánea son menos ruidosas en este sentido, y prima un habitus callado, vinculado a una "premisa introspectiva” (Sáez, 2017, p. 215). Sin embargo, la voz del docente se encuentra presente a lo largo de las clases, ocupando un lugar central (de ahí la importancia del análisis de la performance comunicativa que aborda el trabajo de Osswald, 2011), y a aquella se suman, por momentos, las voces de los alumnos, en forma de preguntas, comentarios, risas y otros sonidos. En este sentido, y como lo plantea Carozzi (2011), "las palabras con que se designa el movimiento aparecen aquí íntimamente ligadas con los modos en que este se enseña, se aprende y se ejecuta" (p. 9).

Como vimos en las descripciones previas, el contacto con el cuerpo del otro es una de las formas de transmisión que permite la incorporación del movimiento. Este modo de transmisión "cuerpo a cuerpo" puede estar dado por el contacto, que aporta una determinada información sobre la posición, el tono, el peso y otras características corporales, o por la manipulación del cuerpo del otro, que permite la percepción de una serie de modificaciones corporales, hasta llegar a la situación deseada (Mora, 2011). Se incluye también aquí, como otro modo de transmisión "cuerpo a cuerpo", el aprendizaje a través de la mirada, la observación y la copia del movimiento.

El aprendizaje típicamente mimético, sin lugar alguno para la palabra, tiene poco lugar en las clases que hemos observado. Su ejemplo más claro está dado por el "aprender de videos" o el "aprender viendo espectáculos", a partir de los cuales se copia el movimiento que se ha observado ${ }^{2}$. Esta situación es referida más frecuentemente en el caso de las acrobacias que en el de la danza contemporánea. Sin embargo, incluso en el caso de la danza, he escuchado a algunas docentes decir que "se inspiran" o "toman cosas" para sus clases, viendo videos. Pro-

2 Una mención aparte merecerían los "tutoriales", en los que a la mostración del movimiento se le suele sumar la palabra explicativa. bablemente, el imperativo de la "búsqueda personal del movimiento", que prima en el ámbito de la danza contemporánea, contribuya a invisibilizar este tipo de prácticas formativas. Por otra parte, en el caso de las acrobacias, esta práctica de copia de movimientos a partir de lo visto en un video suele ser colectiva y estar acompañada de comentarios verbales. En particular, en el caso de las acrobacias aéreas, es frecuente que un acróbata se suba al elemento, y otro, desde abajo, mire el video y le vaya "dictando" los movimientos que tiene que hacer.

No quiero decir con esto que la copia de movimientos no tenga lugar (de hecho, la he observado y descrito tanto para el contexto de las clases de acrobacia como para el de las clases de danza contemporánea), sino que en la mayoría de los casos, esta copia se realiza acompañada o en el marco de un contexto verbal. Es lo que Mora (2011) ha definido como "modo de transmisión cuerpo-palabra-cuerpo" para los casos de distintas danzas escénicas:

El modo de transmisión cuerpo-palabra-cuerpo implica la mediación de la palabra entre los cuerpos. Lo que se dice proviene de una incorporación ya realizada, y se dirige a conseguir que quien escucha logre que su cuerpo comprenda qué hacer. Es decir, se habla para que lo dicho llegue al cuerpo. Quedan incluidos tanto las explicaciones, indicaciones, correcciones y relatos realizados por las y los docentes, como las conversaciones y comentarios realizados entre estudiantes. En el proceso de enseñanza, la transmisión corporal del movimiento es acompañado con palabras en distintos momentos: cuando se nombran pasos, secuencias o modos ya aprendidos y que tienen una determinada denominación, o que ya se han practicado, por lo que se puede decir, por ejemplo, "Como [lo] hicieron la clase pasada"; cuando se utiliza el lenguaje de la anatomía para conocer la biomecánica que permitirá realizar los complicados movimientos, buscando el conocimiento del propio cuerpo para poder controlarlo; y cuando se dan consignas en forma de comparaciones metafóricas, por ejemplo: "Muevan sus brazos como si fueran cisnes", "Caminen como si una cuerda las tirara hacia arriba". Con las palabras, se refuerza lo que el o la docente muestra, y con ellas se busca la internalización de imágenes que se trasladaran al cuerpo (p. 392).

En los contextos que he observado - particularmente en el caso de la danza contemporánea-, he encon- 
trado también un uso de la voz que podría no quedar contenido en el concepto de palabra. Me refiero al uso de sonidos, onomatopeyas y cantos, en los cuales la voz tiene un lugar en la transmisión de información respecto del movimiento por realizar, pero que no está asociada directamente a un significado verbal. Aquí también podríamos incluir las variaciones en el tono de voz que se registran en la performance docente (y de los alumnos), en el transcurso de las clases. Siguiendo a Mora, podríamos proponer un modo de transmisión cuerpo-voz-cuerpo que permita la inclusión de estas otras modalidades.

Como se desprende de la caracterización de Mora y de lo que hemos observado para el caso de la acrobacia y la danza, esta mediación verbal - o vocal- no se puede entender linealmente en términos de "significado", "explicación” o "reglas proposicionales" del movimiento, en lo cual acordamos con Fiske (1997). Sin embargo, disiento con este autor, ya que parece considerar que, al no encontrar estos elementos, la praxis verbal carece de importancia para la comprensión de prácticas como las que aquí analizamos. ${ }^{3}$ Que el bailar y el acrobatear sean habilidades no verbales o no conceptuales no quiere decir que no estén también atravesadas por usos del lenguaje, los cuales pueden ser tanto proposicionales o explicativos como de otro orden ${ }^{4}$.

Esto nos lleva a revisar el uso metafórico del lenguaje, que hemos visto de manera explícita en el caso de la danza contemporánea, pero al cual podríamos atender también en el caso de las acrobacias, en particular si lo abordamos más allá de su definición lingüística específica como desplazamiento de significado entre conceptos, para entenderlo como desplazamiento entre dominios cognitivos (Johnson, 1987) que puede ser utilizado instrumentalmente (Jackson, 1983). En este sentido, las metáforas no son

3 Por otra parte, los elementos verbales que Fiske considera provienen, principalmente, de contextos de entrevistas, y no del registro de las actuaciones verbales que ocurren en el propio contexto de la actividad observada. Esta es otra diferencia con el enfoque planteado en esta tesis, en la que los elementos verbales del contexto de observación se consideran vinculados con los componentes corporales y motrices de la práctica. En este aspecto, concuerdo con la propuesta de Carozzi (2011).

4 Esta aclaración está en sintonía con lo que Faure (1999), en su analisis del aprendizaje de la danza clásica y contemporánea en Francia, denomina "prácticas lenguajeras", para referirse a los usos del lenguaje, más allá de su función comunicativa y objetivante. formulaciones verbales que simbolizan el cuerpo o el movimiento, sino que se encuentran corporalmente enraizadas, y en ello radica su efectividad.

Los cambios en el modo de percibir nuestro cuerpo al cambiar, por ejemplo, el plano en el que nos movemos (una inversión de $180^{\circ}$, en el caso de las acrobacias y su posición invertida, y de $90^{\circ}$, en el caso del trabajo de piso en la danza) generan una desorientación (y una posterior reorientación) que es simultáneamente corporal y mental.

La posición erguida define una relación psico-física con el mundo, de manera que la pérdida de esta posición, de esta "postura", es una pérdida de balance entre lo que ocurre en lo intelectual y en lo corporal de modo simultáneo, un disturbio en el terreno y centro mismo de nuestro ser. Las metáforas de caída y desequilibrio revelan esta conexión integral de lo psíquico y lo físico; no expresan un concepto en términos de una imagen corporal (Jackson, 2010).

La coexistencia de palabras y movimientos es, entonces, fundamental en el aprendizaje de nuevas técnicas corporales. Como lo plantea Jackson, "dentro del campo unitario del cuerpo-mente-habitus, es posible intervenir y efectuar cambios desde cualquiera de estos puntos" (p. 75).

De estas discusiones, se desprende, como consideración metodológica, la importancia de que la inmersión corporal en la práctica y el registro de los movimientos y experiencias implicados no deje de lado los elementos verbales que también forman parte de ella. En este punto, coincido con la propuesta de Carozzi (2011), quien señala que "las palabras con que se designa el movimiento aparecen aquí íntimamente ligadas con los modos en que este se enseña, se aprende y se ejecuta" (p. 9).

En este mismo sentido, observo que en los procesos de aprendizaje de las prácticas analizadas, la palabra y el movimiento, lo muscular y lo intelectual, la mente y el cuerpo coexisten y se articulan dinámicamente. Considero entonces, que en cada una de estas prácticas se ponen en juego vínculos particulares entre el cuerpo, el movimiento y la palabra, que van recortando e intensificando ciertas dimensiones de la experiencia vital. A través de los ejercicios desarrollados en las clases, de las modalidades de realización de los mismos, de las palabras que los acompañan y 
de los vínculos interpersonales que se ponen en funcionamiento en su ejecución, se promueve la reflexividad (incluyendo aquí la reflexividad corporizada [Rodríguez, 2009]) en torno a ciertas sensaciones, percepciones y emociones vivenciadas en estas prácticas, a las cuales se les otorga una significación diferencial, dando lugar a una particular intensificación sensorial y afectiva.

Hasta aquí hemos visto cuestiones generales, que nos permiten avanzar en la comprensión del modo en que se transmiten y aprenden las prácticas corporales. Me interesa también dar cuenta de algunas particularidades observadas en cada caso.

Como plantea Faure (1999), las modalidades de incorporación son dependientes de aquello que se incorpora.

Una experiencia estabilizada (por estar codificada o por ser largamente repetida de modo idéntico) produce esquemas estables (es el ejemplo de la danza clásica, tal como se la enseña tradicionalmente) que deben desarrollarse en un contexto relativamente previsible o controlable para ser activados correctamente, sin introducción de variables; mientras que las experiencias llevadas a cabo en contextos que juegan con la variación de las condiciones de ejecución (como hemos registrado en los cursos de danzas contemporánea que hemos observado) suscitan otras formas de incorporación, así como competencias variables, como la capacidad de adaptación a lo inhabitual y a los vaivenes de las situaciones de efectuación. (Faure, 1999, p. 84, traducción de la autora).

En este sentido, el cuerpo del acróbata que he descrito se asemeja en mayor medida al cuerpo del bailarín clásico que analiza Faure, en tanto se constituye a partir de una serie de ejercicios destinados a la obtención y dominio de un vocabulario técnico: las figuras y los escapes de las acrobacias aéreas, las figuras acrobáticas de las acrobacias de piso. Este vocabulario técnico es el punto de partida para una posterior complejización, experimentación y desarrollo "personales" y "creativos".

En el caso de la danza contemporánea, es mucho más fuerte la ideología de la individualización del conocimiento, y los procesos formativos se organizan siguiendo una lógica cambiante y flexible, en la que los modos en los que se realizan los movimientos son más variables. Asimismo, las coreografías resultantes pueden provenir de lo emergente durante las clases o los ensayos, que, de este modo, no se dirigen a incorporar una serie de movimientos específicos, sino a generarlos, dentro de determinados límites propuestos durante la formación.

Estos diferentes modos de incorporación contribuyen a la formación de competencias y habitus distintos en cada caso: un cuerpo entrenado en un caso, y un cuerpo disponible en el otro (Sáez, 2017, p. 220). A su vez, en cada una de estas prácticas, los tipos de movimientos corporales que se aprenden, ejecutan e incorporan, en conjunto con el contexto verbal de su realización y aprendizaje, intensifican experiencias particulares. A partir de la vivencia que se suscita en estas prácticas, la reflexividad, la elaboración subjetiva y compartida con otros van delimitando y construyendo experiencias particulares que se intensifican en el transcurrir de la práctica: la experiencia de conexión con el cuerpo, en el caso de la danza contemporánea; y la experiencia de la fuerza, la adrenalina y la dificultad, en el caso del circo.

\section{REFERENCIAS}

Bourdieu, P. (1996). Programa para una sociología del deporte. En Cosas dichas (pp 173-184). Barcelona: Gedisa.

Carozzi, M. (ed.). (2011). Las palabras y los pasos. Etnografías de la danza en la ciudad. Buenos Aires: Gorla.

Faure, S. (1999). Les processus d'incorporation et d'appropriation des savoir-faire du danseur. Education et Sociétés: Revue internationale de sociologie de l'éducation, (4), 75-90.

Fiske, A.P. (1997). Learning a culture the way informants do: Observing, imitating, and participating. Los Ángeles: UCLA Department of Anthropology.

Jackson, M. (1983). Thinking through the body: An essay on understanding metaphor. Social Analysis: The International Journal of Social and Cultural Practice, (14), 127-149.

Jackson, M. (2010). Conocimiento del cuerpo. En Cuerpos plurales: antropología de y desde los cuerpos. (S. Citro, ed.). (pp. 59-82). Buenos Aires: Biblos.

Johnson, M. (1987). The body in the mind. Chicago: University of Chicago Press. 
Lambeck, M. (2010). Cuerpo y mente en la mente, cuerpo y mente en el cuerpo. Algunas intervenciones antropológicas en una larga conversación. En Cuerpos plurales. Antropología de y desde los cuerpos. (S. Citro, ed.). (pp. 105-125). Buenos Aires: Biblos.

Mora, A. (2011). El cuerpo en la danza desde la antropología. Prácticas representaciones y experiencias durante la formación en Danzas Clásicas, Danza Contemporánea y Expresión Corporal. [Tesis de doctorado, Universidad Nacional de La Plata]. Repositorio institucional UNLP (en versalitas) http://hdl.handle.net/10915/27179

Osswald, D. (2011). Comunicación y movimiento en la formación dancística independiente porteña. En M. J. Carozzi (ed.), Las palabras y los pasos. Etnografías de la danza en la ciudad (pp. 117-154). Buenos Aires: Gorla.
Rodríguez, M. (2009). Entre ritual y espectáculo, reflexividad corporizada en el candombe. Avá. Revista de Antropología, (14), 145-161.

Sáez, M. (2017). Presencias, riesgos e intensidades. Un abordaje socio-antropológico sobre y desde el cuerpo en los procesos de formación de acróbatas y bailarines/as de danza contemporánea en la ciudad de La Plata. [Tesis de doctorado, Universidad de Buenos Aires]. Repositorio UBA (en versalitas). http://repositorio.filo.uba.ar/ handle/filodigital/4097

Wacquant, L. (2006). Entre las cuerdas. Cuadernos de un aprendiz de boxeador. Avellaneda: Siglo XxI. 